\title{
First stress-tolerant soybean gets go-ahead in Argentina
}

A locally-made transgenic stress-tolerant soybean has passed the first of three regulatory reviews in Argentina, putting it on the path to be the first soybean in the world with such a trait to be commercialized. The technology is slated to improve yield by an average of $10 \%$ and was developed by Rosario, Argentinabased Bioceres and Davis, California-based Arcadia Biosciences in a joint venture called Verdeca.

Key to the technology is that it improves yield in both drought conditions and in normal conditions, says Raquel Lia Chan, a researcher at Universidad Nacional del Litoral in Santa Fe, Argentina, and the National Scientific and Technical Research Council (CONICET), whose institutes licensed the technology to Bioceres in 2012 . Yields tend to improve by $14 \%$ in water stress conditions and $7 \%$ in good conditions, according to Verdeca's five years of field trials, says Federico Trucco, CEO at Bioceres. In absolute numbers, the yield gain is 300 additional kilograms per hectare, he says. That's important to growers, who will be paying a premium for the seeds and will expect a return on their investment, even when the weather is good.

The trait works by enabling the crop to continue to be productive for longer periods during water stress. "Crops tend to shut down fairly quickly when they are under stress. The trick here is to make them think they are not under stress so that they can continue moving forward with photosynthetic machinery a little longer," says Trucco.

To do this, the researchers targeted the ethylene pathway. Soybean was transformed using Agrobacterium to express HB4, a modified version of Hahb4-a homeodomain-leucine zipper (HD-zip) transcription factor from sunflower, along with an Hahb4 native promoter, which is stress inducible. HB4 decreases sensitivity to ethylene, which regulates plant growth under abiotic stress, and thereby helps maintain plant metabolism even during the critical reproductive period, says Gerónimo Watson, chief technology officer at Bioceres. The delay in senescence, they surmise, is coupled with enhanced synthesis of antioxidants and osmoprotectants to enable active photosynthesis for longer periods during drought, increasing grain yields, he says.

The regulatory approval came from CONABIA, the National Advisory Commission on Agricultural Biotechnology, which reviews environmental safety. It is the first of three regulatory bodies in Argentina that must approve a transgenic trait before it can be commercialized in that country. Trucco estimates it will take another 12-18 months to receive clearance from SENASA, the National Animal Health and Agrifood Quality Service. The agency conducts food safety and toxicology reviews of biotech crops and tends to move slowly, says Chan. A third component of Argentina's regulatory system is an economic assessment to determine the impact on Argentinian trade.

Arcadia and Bioceres say they plan to partner with large seed and breeding companies to navigate regulatory processes and commercialize the trait in South America and the US. "Our model is to rely on downstream partners to do the final breeding, make the stacks and do the marketing," says Eric Rey, CEO at Arcadia. The companies have already found one such partnerGDM Seeds in Londrina, Argentina-with which it announced in

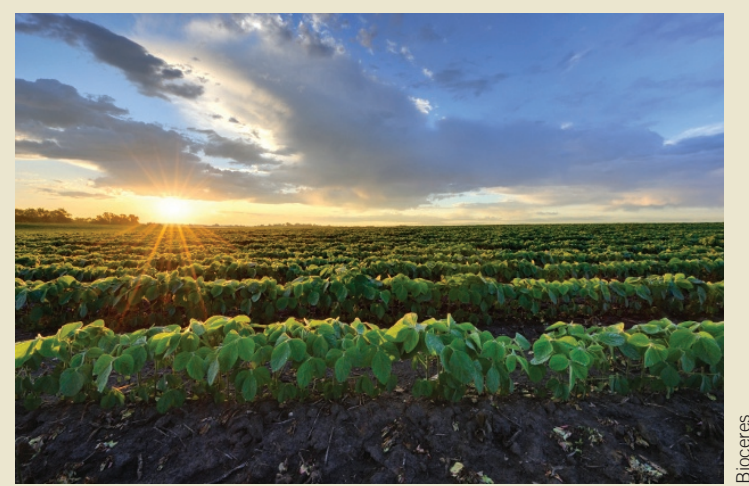

Soybean growing in Argentina's plains.

December 2013 a commercialization partnership for South America. "Building more partnerships like that is part of what's in process," says Rey.

In April this year the companies also announced a partnership with Dow AgroSciences in Indianapolis to generate stacked traits in soybean that combine "Verdeca's agronomic performance and product quality traits with Dow AgroSciences' herbicide-tolerant and insect-resistant traits," according to a joint press release from the companies. HB4 was not listed as one of those, but Rey says it "is certainly within the realm of what could come together in a stack."

At least two other drought-tolerance traits have been commercially approved in other crops. The first was St. Louisbased Monsanto's DroughtGard maize, a variety expressing a Bacillus subtilis cold-shock protein, which was approved for commercial cultivation in the US in 2011. The second was a drought-tolerant sugarcane variety approved in Indonesia in 2013 that expresses glycine betaine from Rhizobium meliloti. At least half a dozen other drought-tolerance traits are in development worldwide, including one in corn from Johnston, lowa-based DuPont Pioneer that, like Verdeca's trait, targets the ethylene pathway (Nat. Biotechnol. 32, 610-613, 2014).

Some researchers contend that 'drought tolerance' in crops is more of a buzzword than a trait. Indeed, Trucco at Bioceres says he'd rather call his company's HB4 soybean a "yield improvement trait," because the mechanism to explain wateruse efficiency or drought tolerance is not known in detail. "We know it correlates with water availability but we also know we can get improved yields [without a] clear drought episode," he says. And bottom line, the value of the trait is measured with yield, he says. "From a marketing perspective, 'drought tolerance' is more appealing. From a first-to-market approach it makes you unique," he says.

"Call it whatever you want. If they can produce more and [reduce losses] due to water deficit, I call it a 'good news trait'," says Eduardo Blumwald, a plant biologist at the University of California, Davis. Argentina's export revenue for soybean is about $\$ 20-25$ billion, and this technology can improve yield by $10 \%$ every year. " $\$ 2.5$ billion is a lot of money for a country like ours," says Trucco.

Emily Waltz Nashville, Tennessee 